\title{
In abdominal myomectomy: the role of ligating uterine arteries bilaterally before performing myomectomy (BUAL- bilateral uterine artery ligation)
}

\author{
Mandal S. ${ }^{1}$, Mandal RD. ${ }^{2}$, Mondal C. ${ }^{3}$, Halder K. ${ }^{4}$, Sreelekshmi M.V. ${ }^{5}$, Chakrobarty P. ${ }^{6}$ \\ ${ }^{1}$ Dr. Sarbeswar Mandal. Associate Professor, ${ }^{2}$ Dr. Rahul Deb Mandal, Assistant Professor, ${ }^{3}$ Dr. Chirantan Mondal, SR \\ Resident, ${ }^{4}$ Dr. Koyel Halder, SR Resident, ${ }^{5}$ Dr. Sreelekshmi M V., SR Resident, ${ }^{6}$ Dr. Pritha Chakrobarty, SR Resident, \\ All authors are affiliated with the Department of Obstetrics and Gynecology, IPGMER-SSKM (PG)H, Kolkata, West \\ Bengal, India.
}

Corresponding Author: Dr. Rahul Deb Mandal, Assistant Professor, Department of Obstetrics and Gynecology, IPGMER-SSKM (PG)H, Kolkata, West Bengal, India. Email: drrdmandal@gmail.com

\begin{abstract}
Aims and Objectives: To determine the impact, efficacy, benefits of such low cost safe technological option (BUAL) in areas where high level surgical interventions are restricted. Methods and Materials: The total sixty six (66)cases have been selected on random basis of which thirty three (33)cases allocated in group A ( $\mathrm{n}=33$ ) (cases) were operated by this method (BUAL) and others in group B $(n=33)$ (controls) were operated by other methods (Bonney's clamp ,tourniquet or vasopressin). Results and Analysis: The results of individual group have been analyzed in the form of primary outcome and secondary outcome. There are statistically significant less blood loss, less transfusion, less operation time with good post-operative recovery and satisfaction by low cost in $\mathrm{Gr}-\mathrm{A}$ (Cases) compare to $\mathrm{Gr}-\mathrm{B}$ (Controls). Conclusion: The bilateral uterine artery ligation should be ligated before starting myomectomy not only open but also laparoscopic method to minimize complications.
\end{abstract}

Keyword: Abdominal open procedure, BUAL, Myomectomy \& reconstruction.

\section{Introduction}

Recent ultrasound data suggested a cumulative incidence at least $70 \%$, uterine myoma originating from the myometrium of the uterus is the most common benign tumor in women with prevalence rates ranging from $20-40 \%$ are noted in different literatures though the incidence as per the histological diagnosis is much more than the clinical diagnosis which approximately $60 \%$ of women above 45 years of age are harboring myoma [1].

Myoma is mostly asymptomatic. Size and location are the main factors that determine if a myoma leads to symptoms and problems. Important symptoms include abnormal uterine bleeding, abdominal discomfort, bloating, painful defecation, backache, urinary frequency or retention and infertility. It is associated with impairment of Health-Related Quality of Life (HRQOL) [2]. The presence of submucous and

Manuscript received: $20^{\text {th }}$ November 2019

Reviewed: $30^{\text {th }}$ November 2019

Author Corrected: $7^{\text {th }}$ December 2019

Accepted for Publication: 11 $1^{\text {th }}$ December 2019 intramural myoma decreases fertility and its removal is beneficial [3]. Patients have multiple options in the management of uterine myomas including observation, medical therapy, uterine artery embolization, high intensity focused ultrasound ablation and as well as surgical methods like myomectomy and hysterectomy. Surgical removal is necessary when the myoma is symptomatic and resistant to medical management or interferes with reproduction. Although uterine artery embolization is now an effective way for managing symptomatic uterine myomas but its effect on future conception remains unclear [4].

Myomectomy is an invasive surgical procedure and can be done abdominally, laparoscopically or by robotic method but in our country more commonly myomectomy operation is performed by abdominal incision where the layered closure of uterus can be achieved easily as laparoscopic myomectomy requires additional equipments but results of robotic myomectomy are yet to be proved better than 


\section{Original Research Article}

laparoscopic method [5], but hysterectomy, blood transfusions, scar dehiscence in future pregnancy and many others has not yet been evaluated [6]. Among available treatment modalities of which mostly in symptomatic myomas where open myomectomy, most likely treatment option despite of introduction of nonsurgical and newer methods available worldwide (USA$40,000 / y r)$ where hemorrhagic(Blood 10ss $>1000 \mathrm{ml})$ complication that controlled by different techniques though individuals having drawbacks but the bilateral uterine arteries ligation (BUAL) not only very effective to minimize blood loss but also safe and no adverse effects on fertility and pregnancy.

The first successful abdominal myomectomy was performed by Atlee, Washington and John in USA, W. Alexander in UK which popularized by Kelly, Cullen, Mayo, Bonney and others. The major concern during the procedure and post-operative period is bleeding due to failure to achieve haemostatic of myometrial vessels and uterine incision. To control hemorrhage and to have a bloodless operative field, Victor Bonney first used clamp around uterine vessels and round ligament, RUBIN used elastic rubber catheter as tourniquet (tourniquet -not effective after removal (J. Reprod Med. 2003) and later Dillon, Ginsberg used vasopressin though individual has drawbacks like trauma to pelvic structures and vasopressin related adverse effects. But the bilateral uterine artery ligation step prior to myomectomy reduces blood loss during operative and post-operative period, make surgical field clear hence reduces operation time [7] missed fibroid may shrink and reduce the recurrence [8] and it is safe and necessary when bleeding is anticipated especially in degenerated myomas [9].

\section{Methods and Material}

Setting: Academic, Research.

Duration \& Type of Study: 1(one) year (19.02.2015-18.02.2016)

Sampling Method: Prospective randomized control study, Clinical Trial, Comparative Study. Sample Size Calculation: 66 (Sixty-six). Gr-A n-33(CASES) \& Gr-B n-33(CONTROLS).

Consolidated standards of reporting trails (consort) statement.

\section{Inclusion criteria}

1) Both nullipara and multipara myoma with symptoms.

2) Myoma with infertility (Infertility-27\%).

3) Myoma with pregnancy loss.

\section{Exclusion criteria}

1) Advanced age with complete family.

2) Endometrial and pelvic Koch's infection

3) Bleeding disorders, anticoagulant therapy, $\mathrm{Hb}<10.5 \%$

4) Premalignant lesion.

5) Severe endometriosis and deformed tubes.
Tulandi et al, Xiadyan et and Holub et al concluded that the step has no adverse effects on uterus, future recanalisation with collateral (6-8 weeks) menstruation (2-5 months) (Effective 97\%- 98\%) and pregnancy occurs more than 40\%-50\% [10]. Therefore, proper haemostasis and layered closure of uterus following myomectomy are very important issues to minimize complications. Haemorrhage is a major concern in myomectomy operation. Bleeding can be prevented if dissection done through the avascular cleft or decreased with mechanical or pharmacologic methods. Use of uterine artery tourniquet during myomectomy causes significant decrease in blood loss.

The studies on myomectomy by different methods concluded blood loss more than $1500 \mathrm{ml}$ with huge transfusion, average operation time two (2) hours (approx) but in our study by this simple, low cost technological step (BUAL) revealed less operation time, less blood loss and transfusion with good wound, satisfactory post-operative recovery and discharge from hospital and statistically significant primary and secondary outcomes. This simple surgical technique should be incorporated during myomectomy not only open but also minimal-access surgery as method to control hemorrhage.

This study statistically showed that B.U.A.L. is better that's why this can be done safely and effectively as a low cost, low technology option in areas where high level medical technology restricted like India as the primary and secondary outcomes of this method is more effective, safe and convenient to other haemostatic techniques [11]. 


\section{Original Research Article}

\section{Consolidated Standards of Reporting Trails (Consort) Statement}

Allocation done Sequentially Numbered Opaque Sealed Enveloped (SNOSE), where Sequence generated computerized random number generator and envelopes size, shape, weight confirmed equally having -Code-Gr-A(CASES), Code-Gr-B (controls).

Aluminums foil inside envelopes was used to render envelops impermeable to light. Envelops number in advanced, opened sequentially only after participants' name and other details written on appropriate envelops.

Envelops contains carbon papers which essential for audit trial. Must registry entry of patients 'profile.

Enrollment-
Assessed for eligibility $(\mathrm{N}=66)$

Excluded $(\mathrm{N}=0)$

Not meeting inclusion criteria $(\mathrm{N}=0)$

Declined to participate $(\mathrm{N}=0)$

Others Reasons $(\mathrm{N}=0)$

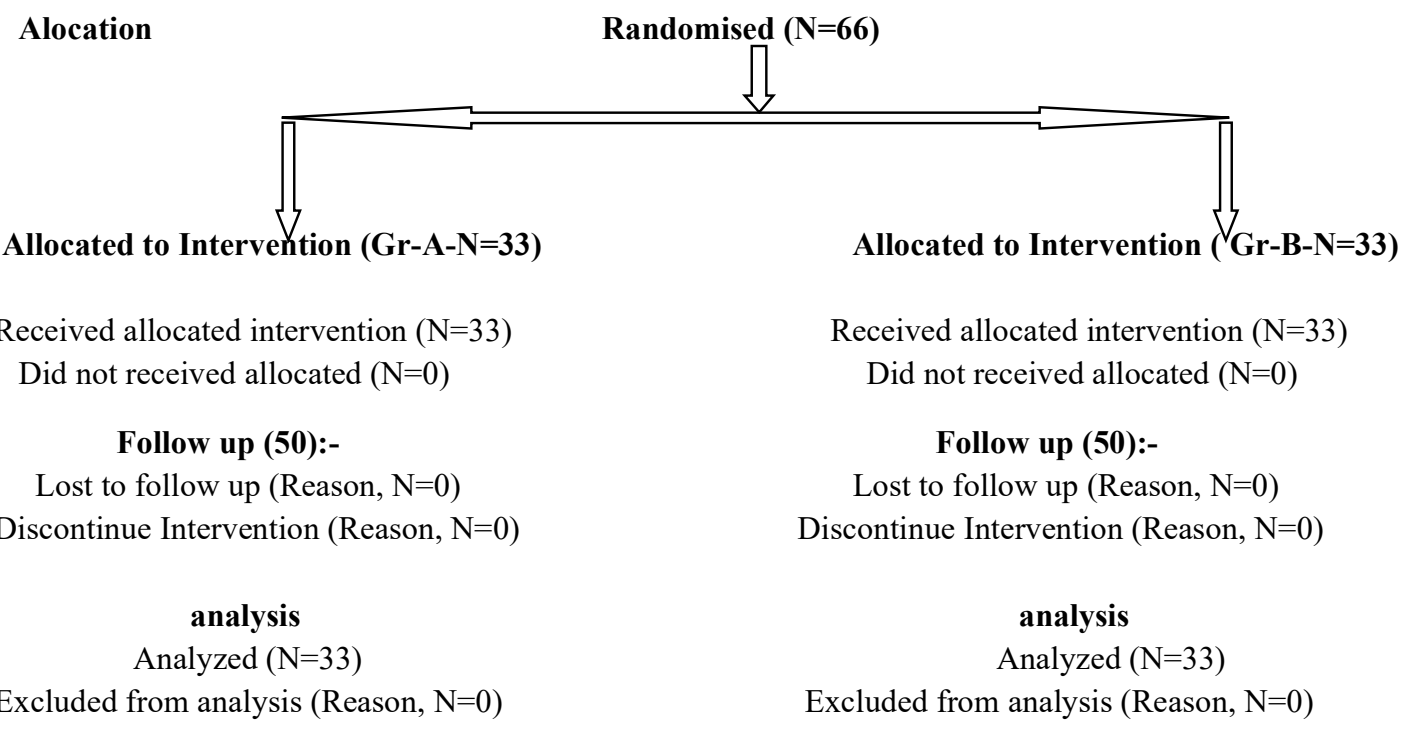

Data collection procedure: Allocation done as Sequentially Numbered Opaque Sealed Enveloped (SNOSE), where Sequence generated computerized random number generator and envelopes size, shape, weight confirmed equally having -Code-Gr-A(CASES), Code-Gr-B(CONTROLS).

Aluminums foil inside envelopes was used to render envelops impermeable to light. Envelops number in advanced, opened sequentially only after participants' name and other details written on appropriate envelops. Envelops contains carbon papers which essential for audit trial. Must registry entry of patients 'profile.

Data analysis: The outcomes of individual groups analysed as-

*Primary outcome (organ damage/failure, blood loss, transfusion)

* secondary outcome (operation time, mobilization time, oral intake time, analgesic, pain relieved and satisfaction)

*secondary outcome (wound complications, hospital stay, costs and readmission) tabulated and statistical significant calculated by GRAPH-PAD SOFTWARE in TABLE-1, TABLE-2.

Ethical Consideration \& Permission: Duly applied, approved by the Institutional Ethics Committee Certificate enclosed.

Any Scoring System: - It is associated with impairment of Health-Related Quality of Life (HRQOL).

Surgical Procedure: THE bilateral uterine artery ligation-bual.

Place of Study: Department of Gynaecology and Obstetrics, IPGMER - SSKM HOSPITAL. West Bengal. India. 


\section{Original Research Article}

As per O'Leary uterine artery ligation method (7), laparotomy -utero vesical fold (anterior POD) opened up- bladder pushed down which moves ureters laterally-Atraumatic needle No-O-PGS-passed through 2-3cms below the internal os with $2-3 \mathrm{cms}$ myometrium which tied anteriorly and same to be done opposite side. After initial this simple step removal of myomas and reconstruction done as per conventional methods in GR-A(cases) and other methods (Bonney's clam, Elastic rubber cather, Vasopressin local infiltration) prior myomectomy and reconstruction done in GR-B(controls).

Procedure- We prefer to ligate the ascending branch of the uterine artery anteriorly during myomectomies. The uterovesical fold of the peritoneum is opened and the bladder is pushed down. This mobilizes the ureters laterally and prevents them being included in the suture. The uterine vessels are identified on either side and ligated. As per O'Leary uterine artery ligation method (12), laparotomy -utero vesical fold (anterior POD) opened up- bladder pushed down which mobilizes ureters laterally-Atraumatic needle No-O-PGS-passed through 2-3cms below the internal os with 2$3 \mathrm{cms}$ myometrium which tied anteriorly and same to be done opposite side. After initial this simple step removal of myomas and reconstruction done as per conventional methods in GR-A (cases) and other methods(Bonney's clam, Elastic rubber cather, Vasopressin local infiltration) prior myomectomy and reconstruction done in GR-B (controls). There can be technical difficulties in approaching the uterine vessels in the case of large myomas. There can be some venous bleeding if the uterine vein is accidentally punctured. In such cases the suturing is completed and the venous bleed stops by itself. Once the uterine are occluded bilaterally, the myoma turns pale. This devascularizes the myoma and decreases the blood loss during the procedure. This reduces pulse pressure to uterus as $90 \%$ and recanalisation and collateral circulation will be established within 6-8weeks with a success rate of 95\%- 98\% (WATERSThe American Journal of Radiology).

\section{Results}

The outcomes of individual groups analysed as *Primary outcome(organ damage/failure, blood loss, transfusion) *secondary outcome (operation time, mobilization time, oral intake time, analgesic, pain relieved and satisfaction) *secondary outcome (wound complications, hospitalstay,costs and readmission) tabulated and statistical significant calculated by Graph-pad software in Table-1, Table-2.

Table-1: Primary outcomes.

\begin{tabular}{|c|c|c|c|}
\hline Indicators & GR-A(N==33) & GR-B(N=33) & Conclusion \\
\hline \multicolumn{4}{|l|}{ Organ damage/failure: } \\
\hline Ureter & $1 / 32$ & $8 / 25$ & $\mathrm{P}=0.0268$ \\
\hline Bladder & 3/30(stained urine) & $12 / 21$ (stained urine) & $\mathrm{P}=0.0169$ \\
\hline G.I.T & $1 / 32$ & $9 / 24$ & $\mathrm{P}=0.0129$ \\
\hline Vessels & $3 / 30$ & $11 / 22$ & $\mathrm{P}=0.0326$ \\
\hline \multicolumn{4}{|l|}{ Blood Loss: } \\
\hline Volume drain(operation) & $* 20, * 5, * 28.72$ & $* 50, * 8, * 45.96$ & $\mathrm{P}<0.0001$ \\
\hline Drains (48 hrs) & $* 150, * 50,287.23$ & $* 300, * 50, * 287.23$ & $\mathrm{P}=0.0378$ \\
\hline $\mathrm{Hb}$ Drop & $1, .05, .28$ & $2, .05, .28$ & $\mathrm{P}<0.0001$ \\
\hline Mops Wt (wet -dry) & $400,50,287.23$ & $800,50,287.23$ & $\mathrm{P}<0.0001$ \\
\hline Pcv drop & $1.8, .01, .0574$ & $2.7, .05, .28727$ & $\mathrm{P}<0.0001$ \\
\hline \multicolumn{4}{|l|}{ Transfusion Required: } \\
\hline Blood & 03/30(01 unit) & $12 / 21$ (03units) & $\mathrm{P}=0.0169$ \\
\hline F.F.P. & $00 / 33$ & $33 / 0$ ( $\geq 1$ unit $)$ & $\mathrm{P}<0.0001$ \\
\hline Platelets & $00 / 33$ & $33 / 00$ ( $\geq 1$ unit $)$ & $\mathrm{P}<0.0001$ \\
\hline Volume Expanders & $03 / 30$ & $27 / 05$ & $\mathrm{P}<0.0001$ \\
\hline Hypotension/Hypertension & 05/28(BP increased) & 25/08(BP decreased) & $\mathrm{P}<0.0001$ \\
\hline Chest Discomfort & $2 / 31$ & $15 / 18$ & $\mathrm{P}=0.0005$ \\
\hline I.T.U/C.C.U Care & $00 / 33$ & $08 / 25$ & $\mathrm{P}=0.0048$ \\
\hline Death & NIL & 01 & Not applicable. \\
\hline
\end{tabular}

Fisher's Exert Test (FET). Unpaired-t-test (UTT). MEAN.SEM.SD. 
Original Research Article

Table-2: Secondary outcomes.

\begin{tabular}{|c|c|c|c|c|}
\hline INDICATORS & $\begin{array}{c}\text { Group A } \\
(n=33) \text { (Cases) }\end{array}$ & $\begin{array}{c}\text { Group B } \\
(\mathrm{n}=\mathbf{3 3})(\text { controls })\end{array}$ & p Value & Reference \\
\hline Operation time & $50.5 \pm 8.7 \mathrm{mins}$ & $76.3 \pm 9.4 \mathrm{mins}$ & $\mathrm{P}<0.0001$ & Unpaired-t-test \\
\hline Angle haematoma & $\begin{array}{l}\text { BUAL-Site-3 } \\
\text { Incision-4 }\end{array}$ & $\begin{array}{c}\text { Clamps/tourniquet } \\
\text { site- } 15 . \\
\text { Incision-10 }\end{array}$ & $\mathrm{P}=0.0010$ & Fisher's Exat Test \\
\hline Stitch line haematoma & 10 & 36 & $\mathrm{P}<0.0001$ & Fisher's Exert Test \\
\hline Approximation failure & 11 & 34 & $\mathrm{P}=0.0002$ & Fisher's Exert Test \\
\hline Stitch whole injury & 14 & 30 & $\mathrm{P}=0.0099$ & Fisher's Exert Test \\
\hline Cut through and avulsion & 7 & 24 & $\mathrm{P}=0.0007$ & Fisher's Exert Test \\
\hline Mobilisation time & $8,2,11.49$. & $18,4,22.98$. & $\mathrm{P}=0.0288$ & UTT-TTP \\
\hline Oral feeding time & $10,2,11.49$ & $20,4,22.98$ & $\mathrm{P}=0.0288$ & UTT-TTP. \\
\hline Post-operative pain & $\begin{array}{l}\text { Less and good } \\
\text { satisfaction } \\
(30 / 3)\end{array}$ & $\begin{array}{c}\text { More and poor } \\
\text { satisfaction }(0 / 33)\end{array}$ & $\mathrm{P}<0.0001$. & Fisher's Exert Test \\
\hline Analgesic needs and satisfaction & $12,2,11.49$ & $24,4,22.49$. & $\mathrm{P}=0.0093$ & UTT-TTP. \\
\hline Febrile complication & 5 & 20 & $\mathrm{P}=0.0022$ & Fisher's Exert Test \\
\hline $\begin{array}{l}\text { Wound healing, Infection, Pain } \\
\& \text { hardness, Complication. }\end{array}$ & 6 & 23 & $\mathrm{P}=0.0010$ & Fisher's Exert Test \\
\hline Re- admission & 2 & 5 & NA & NA \\
\hline Hospital stay & $7,1,5.74$ & $14,2,11.49$ & $\mathrm{P}=0.0026$ & UTT-TTP. \\
\hline
\end{tabular}

Fisher's Exert Test (FET). Unpaired-t-test (UTT). MEAN.SEM.SD.

The primary outcomes in forms of organs failure or damages on ureters, bladder, G I T and Vessels are statistically less in our study group compared to controls $(\mathrm{P}=0.0129-\mathrm{P}=0.0326)$, Estimated Blood Loss (EBL) (measured in form of drains, mops, $\mathrm{Hb}$ drops \& PCV Drops) are statistically less in our study group compared to controls ( $\mathrm{P}<0.0001-$ $\mathrm{P}=0.0378$ ), Required transfusion in form of blood, FFP, Platelets, Volume Expanders are statistically less in our study group compared to controls $(\mathrm{P}<0.0001-\mathrm{P}=0.0169)$, cardiovascular and other complications(Hypotension/Hypertension, Chest Discomfort, I.T.U/C.C.U Care) are statistically less in our study group compared to controls( $\mathrm{P}<0.0001-\mathrm{P}=0.0048)$ without any mortality. The secondary outcomes in forms of Operation time $(\mathrm{P}<0.0001)$, Angle haematoma $(\mathrm{P}=0.0010)$, Stitch line haematoma $(\mathrm{P}<0.0001)$, Approximation failure $(\mathrm{P}=0.0002)$, Stitch whole injury $(\mathrm{P}=0.0099)$, Cut through and avulsion $(\mathrm{P}=0.0007)$, Mobilisation time $(\mathrm{P}=0.0288)$, Oral feeding time $(\mathrm{P}=0.0288)$, Post-operative pain $(\mathrm{P}<0.0001)$, Analgesic needs and satisfaction $(\mathrm{P}=0.0093)$, Febrile complication $(\mathrm{P}=0.0022)$, Wound healing, Infection, Pain \& hardness, Complication ( $\mathrm{P}=0.0010)$, Re- admission, Hospital stay( $\mathrm{P}=0.0026)$ are statistically better in our study group compared to controls.

\section{Discussion}

We have described a newly developed technique to treat symptomatic fibroids. A uterine depletion procedure followed by myomectomy, by the abdominal route, is a very promising advance in the treatment of symptomatic fibroids. Bonney [13] designed a special clamp to compress the uterine arteries, whereas Lock [14] recommended the use of rubber-shod sponge forceps for occlusion of the uterine and ovarian arteries, and Rubin [15] used a rubber catheter to encircle the lower uterine segment for occlusion of the uterine vessels. Although these authors recommend releasing the compression approximately every 10-20 minutes to prevent ischemic necrosis to the myometrium, the need for this has not been proved by empirical study. 


\section{Original Research Article}

Anatomical Considerations: The uterus is primarily supplied by the uterine artery, which is a branch from the anterior division of the internal iliac artery. The vascularity of the uterus is rich as it also receives its blood supply from other sources. The myometrium has an extremely rich blood supply. First, the blood reaches the uterus primarily through the uterine arteries, whose sizes are about 2 to $6 \mathrm{~mm}$ in diameter. Second, small $(0.5 \mathrm{~mm})$ communicating arteries connect the uterus with the ovarian arteries. Third, many named arteries have the potential to supply blood to the uterus: inferior mesenteric, lumbar, vertebral, middle sacral, deep iliac circumflex, inferior epigastric, medial femoral circumflex, and lateral femoral circumflex arteries. Fourth, innumerable very small, unnamed arteries reach the uterus from the broad ligament and retroperitoneum. Unlike the uterus, which has various blood supplies, the vascular supply to the fibroids comes exclusively from the uterine arteries $[16,17,18]$.

Procedure- We prefer to ligate the ascending branch of the uterine artery anteriorly during myomectomies. The uterovesical fold of the peritoneum is opened and the bladder is pushed down. This moves the ureters laterally and prevents them being included in the suture. The uterine vessels are identified on either side and ligated. We use No. 1 delayed absorbable sutures for ligating the uterine vessels. There can be technical difficulties in approaching the uterine vessels in the case of large myomas. There can be some venous bleeding if the uterine vein is accidentally punctured. In such cases the suturing is completed and the venous bleed stops by itself. Once the uterine are occluded bilaterally, the myoma turns pale. This devascularizes the myoma and decreases the blood loss during the procedure.

Effects- The hypothesis further postulates that hours later the clot within the myometrium lyses and the uterus is reperfused through the collateral arteries [19]. Burbank and colleagues put forward this 'transient uterine ischemia' hypothesis, to explain the mechanism of uterine artery occlusion. They proposed that after uterine artery occlusion, both the myometrial and myoma vessels were occluded by clotting, resulting in organ ischemia [20], which was shown both through pathological observations and with magnetic resonance imaging (MRI) [21,22].

The major advantage of ligating the uterine vessels before myomectomy is that blood loss during the procedure is considerably reduced. Studies have also shown that there is shrinkage of very small fibroids that are not removed during the surgery, which prevents recurrence of new fibroids.
Pregnancy after uterine artery ligation- Successful pregnancy rates have been reported in literature following bilateral internal iliac ligation [23]. Fertility and pregnancy following selective ligation of the uterine arteries has also been reported in recorded in the world's medical literature [24,25]. Holub et al., [26] assessed pregnancy outcomes and deliveries after uterine artery transection in symptomatic women with fibroids. Fetal growth and umbilical Doppler findings remained normal in all cases.

Concerns of uterine artery ligation during myomectomy- If it is technically possible to ligate the uterine vessels before myomectomy, especially in large myomas, then bleeding during the procedure would not be a major concern. Including the ureters in the suture is another concern. If the uterovesical fold of the peritoneum is opened and the bladder pushed down, the ureters move laterally and the chance of including them in the suture is less.

Fertility after uterine artery ligation- Tulandi et al [27] have described that due to transient ovarian ischemia, some degree of ovarian reserve appears to be lost when the ovaries are inadvertently embolized. Blood flow reaches the ovary either from the ipsilateral ovarian artery or from the ipsilateral utero-ovarian communicating arteries and does so depending on the local arterial and arteriolar resistances [28]. Consequently, when uterine artery embolization (UAE) is performed with sufficiently small embolic particles, approximately $60 \%$ of ovaries are vulnerable to embolization. In this technique we selectively isolate the uterine arteries and ligate them which exclude the possibility of ligating the utero-ovarian communicating artery and does not cause decreased ovarian reserve or ovarian failure. Most studies suggest that unlike uterine artery embolization, uterine artery occlusion is a selective procedure and does not cause decreased ovarian reserve.

Laparoscopic myomectomy with uterine artery ligation- Devascularization of the myomas by selective uterine artery ligation is the basis for many treatment modalities used for symptomatic myomas ligation of the uterine arteries [29,30].

Uterine artery embolization (UAE) for the treatment of uterine myomas was first reported in 1995 [31]. with post embolization syndrome affects up to $26 \%$ of the patients and contributes to prolonged institutional stays (including readmission), heavy analgesic use, and delayed return to normal activities [32], studied the effect of uterine artery occlusion in myomectomy for 


\section{Original Research Article}

uterine myomas and stated with conclusion that better hemostasis controls. The studies on myomectomy by different methods concluded blood loss more than $1500 \mathrm{ml}$ with huge transfusion, average operation time two (2) hours (approx) but in our study by this simple, low cost technological step (BUAL) revealed less operation time, less blood loss and transfusion with good wound, satisfactory post-operative recovery and discharge from hospital and statistically significant primary and secondary outcomes. This simple surgical technique should be incorporated during myomectomy not only open but also minimal-access surgery as method to control hemorrhage.

\section{Conclusion}

Myomectomy is an effective treatment option for those women who have symptomatic fibroids and wish to preserve fertility or retain the uterus. Recent studies suggest that the morbidity of abdominal myomectomy and hysterectomy are similar, although hemorrhage and transfusion requirements in women with larger uteri, associated with a high rate of recurrence and adhesions.

Here, we used this new method the bilateral uterine arteries ligation (B.U.A.L) during myomectomy having decrease in intraoperative bleeding and complete treatment success when followed by it. The decrease in blood loss is due to the uterine artery ligation, similar to the action of a clamp to compress the uterine arteries or a rubber catheter around the lower uterine segment that occludes the uterine vessels with the injection of diluted vasopressin cannot mask the arterial bleeding for myomectomy.

Though intraoperative blood loss was ranging from 20 $350 \mathrm{~mL}$ for the uterine depletion procedure with myomectomy in other methods, in this study the blood loss is statistically less $(\mathrm{p}<0.0001)$.

On compared to UAE \& LBCUB, we ligate only the uterine artery in the procedure, which does not block the blood supply to the ovary from the infundibulopelvic ligament or anastomotic sites of the uterine arteries and the ovarian arteries which might explain why the pregnancy rate without evidence of intrauterine growth retardation or other maternal or fetal problems was not statistically different between the two groups.

The bilateral uterine arteries ligation (B.U.A.L) may be used when bleeding in anticipated or occurs during myomectomy to avoid hysterectomy because of recanalisation, collateral circulation and future reproduction not affected as a more effective preliminary effective step not only reducing blood loss but also to helps to shrink small fibroids and prevent the recurrence of fibroids must be advocated and recommended its routine use at open myomectomy as safe and convenient to other haemostatic methods generally used in this operation.

\section{Drawbacks \& Limitation}

- On average, an additional 10 minutes of operating time was required for the uterine depletion procedure when combined with either an abdominal myomectomy.

- The learning curve for ligation of the uterine arteries by the abdominal route might be longer for inexperienced surgeons.

- If this uterine depletion procedure is to be routinely performed in myomectomy in the future, more surgical training will be required.

- It is single centre study, with small sample size required long follow-up required especially reproductive life in future not properly evaluated.

\section{What this study adds to existing knowledge?}

This step should be adopted as prophylactic ,integral and debut step by the surgeons specially in developing World where inadequate blood transfusion as this is a preliminarily more effective step for reducing blood loss, advocated and recommended its routine use as safe and convenient to other haemostatic methods not only in this operation and must be incorporated in G\&O training for enriched and taught surgeons for other vaginal surgery.

\section{Author's contribution}

Dr. Sarbeswar Mandal. assisted by Dr. Rahul Deb Mandal:Defining-Planning-Implimentation-Monitoring \& Fine- tuning- Evaluating- Capitalizing. Detail description of situation and analysis to find out with prioritizing the problems to identify root, real problem which to be addressed for turning ideas into research Questionnaires.-Title Formation--- Review of Literature,- research design--- implimentationDuration (Time frame), Part \& Parcels materials (Money, Logistics etc), Resources (Human) deployment, Writing study protocol-------- (Time, Materials, HRP), Budget---(Manpower, Materials, Money, Funding Source, Lobbying), Ethics \&Other approval- (Consent, Ethics Submission, Scientific Board Submission). 


\section{Original Research Article}

Dr.Chirantan Mondal, Dr. Koyel Halder, Dr Sreelekshmi M V. \& Dr Pritha Chakrobarty: Assisted to Conduct study (Forms, Data captures, Ensure Compliances), data Processing (Data collection, Statistical analysis, Interpretation, Explanation, Archiving of Data), reporting \& dissemination (Report writing, Presentation, Publication).

Final Manuscript - Prepared by - Dr. Sarbeswar Mandal, with assistance by Dr. Rahul Deb Mandal.

*Manuscripts review \& approval -making a meeting with all members (all authors) discussed, criticized, modified, rectified and finally edited with approval.

Acknowledgement- Authors would like to thank all the patients recruited in the study and all the members of the Department of Obstetrics and Gynecology and thankful to Institutional Ethics Committee, IPGMERSSKMH, Kolkata, West Bengal, India.

Funding: No funding sources

Conflict of interest: None declared

Ethical Approval: This study was approved by the Institutional Ethics Committee

\section{References}

1. Okolo S. Incidence, aetiology and epidemiology of uterine fibroids. Best Practice \& Research Clin Obstet \& Gynaecol. 2008; 22(4): 571-588. doi: 10.1016/j. bpobgyn. 2008.04.002. Epub 2008 Jun 4.

2. Downes E, Sikirica V, Gilabert-Estelles J, Bolge SC, Dodd SL, Maroulis C, et al. The burden of uterine fibroids in five European countries. Eur $\mathrm{J}$ Obstet Gynecol Reprod Biol. 2010;152(1):96-102. doi: 10. 1016/j. ejogrb. 2010.05.012. Epub 2010 Jul 3.

3. Pritts EA, Parker WH, Olive DL. Fibroids and infertility: an updated systematic review of the evidence. Fertil Steril. 2009;91(4):1215-1223. doi: 10. 1016 /j. fertnstert.2008.01.051. Epub 2008 Mar 12.

4. Kitson S, Macphail S, Bulmer J, et al. Is pregnancy safe after uterine artery embolisation. BJOG. 2012; 119: 519-21. [PubMed] [Google Scholar].

5. Bedient CE, Magrina JF, Noble BN, Kho RM. Comparison of robotic and laparoscopic myomectomy. Am J Obstet Gynecol. 2009;201(6):566e1-566e5. doi: 10.1016/j.ajog.2009.05.049. Epub 2009 Aug 15.

6. Paul GP, Naik SA, Madhu KN, Thomas T. Complications of laparoscopic myomectomy: A single surgeon's series of 1001 cases. Australian and New Zealand Journal of Obstet and Gynecol. 2010; 50(4): 385-390. doi: 10.1111/j.1479-828X.2010.01191.x.

7. Lik WM, Tzeng CR, Yi-JenC, Wang PH. Combining the uterine depletion procedure and myomectomy may be helpful for treating symptomatic fibroid. Fertil Steril.2004;82(1):205-210.doi:https://doi.org/10. 1016/j. fertnstert.2004.01.026.

8. Base JH, Chong GO, Seong WJ, Hong DG, Lee YS.Benefit of uterine artery ligation in laparoscopic myomectomy.Fertil Steril. 2011;95(2):775-778. doi: 10.1016/j.fertnstert.2010.07.1079.

9. Akinda OI, Fabamwo AO, Akinda RA, Ottum TA, Akinniyi A, Akpan AE. Uterine artery ligatiomn for treatment of fibroid. Acts Obstet Gynecol Scand.2009; 88(1):59-62. doi: 10.1080/00016340802632366.

10. Sinha R, Hegde A,Warty N, Mahajan C. Laparoscopic myomectomy: Enucleation of myoma by morcellation which attached to uterus. J Minimum Invasive Gynecol.2005;12(3):284-289. doi: https://doi. org/ 10.1016/j.jmig.2005.03.018.

11. Sapmaz E, Celik H, Altungil A. Bilateral uterine artery ligation VS tourniquets use for haemostasis in caesarean myomectomy. The J Reproduct Med. 2003, 48(12):950-954.

12. O'Leary JL, O' Leary JA. Uterine artery ligation in control of intractable PPH. Am J Obstct Gynae 1966; 94(7):920-924.

13. Edwards RD, Moss JG, Lumsden MA, Wu O, Murray LS, Twaddle S, et al. Uterine-artery embolization versus surgery for symptomatic uterine fibroids. N Engl J Med. 2007;356:360-370. doi: 10. 1056/ NEJMoa062003.

14. Cheng Z, Yang W, Dai H, Hu L, Qu X, Kang L. Laparoscopic uterine artery occlusion combined with myomectomy for uterine myomas. J Minim Invasive Gynecol. 2008; 15(3): 346-349. doi: 10.1016/j.jmig. 2008. 01.005. Epub 2008 Mar 20.

15. Wang PH, Liu WM, Fuh JL, Chao HT, Chao KC, Yuan CC. Laparoscopic uterine vessel occlusion in the treatment of women with symptomatic uterine myomas with and without adding laparoscopic myomectomy: 4Year Results. J Minima Invasive Gynecol. 2008; 15(6): 712-718. doi: 10.1016/j.jmig.2008.08.005. 


\section{Original Research Article}

16. Lipshutz B. A composite study of the hypogastric artery and its branches. Ann Surg. 1918;67(5):584608. doi: 10.1097/00000658-191805000-00012.

17. Borell U, Fernstrom I. The adnexal branches of the uterine artery. An arteriographic study in human subjects. Acta Radiol. 1953;40(6):561-582.

18. Burchell RC. Arterial physiology of the human female pelvis. Obstet Gynecol. 1968;31(6):855-860.

19. Lichtinger M, Burbank F, Hallson L, Herbert S, Uyeno J, Jones M. The time course of myometrial ischemia and reperfusion after laparoscopic uterine artery occlusion-Theoretical implications. J Am Assoc Gynecol Laparosc. 2003;10(4):553-563. doi: 10.1016/ S1074-3804(05)60168-5.

20. Burbank F, Hutchins FL., Jr Uterine artery occlusion by embolization or surgery for the treatment of fibroids: A unifying hypothesis-transient uterine ischemia. J Am Assoc Gynecol Laparosc. 2000;7(4):S1S49. doi: 10.1016/S1074-3804(05)60633-0.

21. Liu WM, Tzeng CR, Yi-Jen C, Wang PH. Combining the uterine depletion procedure and myomectomy may be useful for treating symptomatic fibroids. Fertil Steril. 2004;82(1):205-210.doi: https:// doi. org/10.1016/j.fertnstert.2004.01.026

22. Sinha R, Hegde A, Warty N, Patil N. Laparoscopic. Excision of Very Large Myomas. J Am Assoc Gynecol Laparosc. 2003;10(4):461-468.

23. Shinagawa S. Extraperitoneal ligation of the internal iliac arteries as a life- and uterus-saving procedure for uncontrolled postpartum hemorrhage. Am J Obstet Gynecol. 1964; 88:130-131.

24. Lenzi G. Pregnancy after ligation of uterine arteries. Attual Ostet Ginecol. 1969;15(1):31-35.

25. Liberman G. Normal labor after ligation of major vessels of the uterus. Akush Ginekol.1966;42(12):45-46
26. Holub Z, Lukac J, Kliment L, Urbanek S. Pregnancy outcomes and deliveries following laparoscopic transsection of uterine vessels: A pilot study. Eur J Obstet Gynecol Reprod Biol. 2006; 125 (2): 165-170. doi: https :// doi. org/10. 1016/j. ejogrb. 2005.06. 021 .

27. Tulandi T, Sammour A, Valenti D, Child TJ, Seti L, Tan SL. Ovarian reserve after uterine artery embolization for leiomyomata. Fertil Steril. 2002; 78 (1): 197-198. doi: https://doi.org/10.1016/S0015-0282 (02) 03164-3.

28. Ryu RK, Chrisman HB, Omary RA, Miljkovic S, Nemcek AA, Jr, Saker MB, et al. The vascular impact of uterine artery embolization: Prospective sonographic assessment of ovarian arterial circulation. J Vasc Interv Radiol. 2001;12(9):1071-1074. doi:10.1016/s1051-0443 (07)61594-2.

29. Liu WM. Laparoscopic bipolar coagulation of uterine vessels to treat symptomatic leiomyomas. J Am Assoc Gynecol Laparosc. 2000;7(1):129-131.

30. Edwards RD, Moss JG, Lumsden MA, Wu O, Murray LS, Twaddle S, et al. Uterine-artery embolization versus surgery for symptomatic uterine fibroids. N Engl J Med. 2007;356:360-370. doi: 10. 1056/ NEJMoa062003.

31. Cheng Z, Yang W, Dai H, Hu L, Qu X, Kang L. Laparoscopic uterine artery occlusion combined with myomectomy for uterine myomas. J Minim Invasive Gynecol. 2008; 15(3): 346-349. doi: https://doi.org/10. $1016 /$ j. jmig.2008.01.005

32. Wang PH, Liu WM, Fuh JL, Chao HT, Chao KC, Yuan CC. Laparoscopic uterine vessel occlusion in the treatment of women with symptomatic uterine myomas with and without adding laparoscopic myomectomy: 4Year Results. J Minima Invasive Gynecol. 2008; 15(6): 712-718. doi: 10.1016/j.jmig.2008.08.005

\section{How to cite this article?}

Mandal S, Mandal RD, Mondal C, Halder K., Sreelekshmi M.V, Chakrobarty P. In abdominal myomectomy: the role of ligating uterine arteries bilaterally before performing myomectomy (BUAL- bilateral uterine artery ligation). Obs Rev: $J$ Obstet Gynecol 2019;5(5):209-217.doi:10.17511/joog.2019.i05.01. 